\title{
A Feedback Control System with Reference Governor for a Solar Membrane Distillation Pilot Facility
}

\author{
Juan D. Gil ${ }^{\mathrm{a}}$, Lidia Roca ${ }^{\mathrm{b}}$, Guillermo Zaragoza ${ }^{\mathrm{b}}$, Manuel Berenguel ${ }^{\mathrm{a}, *}$ \\ ${ }^{a}$ Centro Mixto CIESOL, ceiA3, Universidad de Almería, Departamento de Informática. \\ Ctra. Sacramento s/n, Almería 04120, Spain; juandiego.gil@ual.es; beren@ual.es \\ ${ }^{b}$ Centro Mixto CIESOL, CIEMAT-Plataforma Solar de Almería, Ctra. de Senés km. 4,5 \\ Tabernas 04200, Almería 04120,Spain; lidia.roca@psa.es; guillermo.zaragoza@psa.es
}

\begin{abstract}
This work presents the development of a feedback control system for a pilot membrane distillation facility powered with solar energy located at Plataforma Solar de Almería (PSA), Spain. The control system allows to fix a suitable operating temperature at the inlet of the distillation system, improving the operation quality. Four direct control schemes based on Proportional Integral (PI) controllers and Feedforward (FF) are designed as well as a reference governor which generates temperature references for the heat generation circuit direct control layer. Simulations and experimental tests are shown to demonstrate the effectiveness of the proposed scheme.
\end{abstract}

Keywords: Air-gap membrane distillation, feedforward, reference governor, solar energy, PI controllers.

\section{Introduction and literature review}

Nowadays, water scarcity is one of the main challenges of the World. The demand of fresh water for human use, agriculture and industrial purposes is increasing steadily, reducing the water reservoirs. Consequently, desalination 5 technologies have become a necessity, specially in dry areas with water shortage. Due to the large amount of energy required, desalination technologies must be associated with renewable energy sources for their economical sustainability [1, 2]. Using renewable energy for desalination not only sorts out the water problem but also replaces traditional sources like fossil fuels, thus contributing to efficient environment development [3]. Due to the high solar irradiance available in places with lack of water, solar energy is the most suitable renewable source for desalination processes.

In this context, Solar Membrane Distillation (SMD) is an appropriate technology for developing small-scale desalination systems in remote areas with good

\footnotetext{
* Corresponding author.

Email address: beren@ual.es (Manuel Berenguel)
} 
15 solar irradiance conditions [4, 5]. This technology stands out for its independent features such as easy automation and low thermal energy requirements. It should be noted that SMD has not been yet commercialized due to some technical design problems and uncertainties associated with economic and energetic costs [6]. Therefore, different kinds of modules and Membrane Distillation (MD)

20 configurations have been evaluated in the recent years in terms of thermal efficiency and distillate production [7, 8]. The experimental campaigns carried out in these studies require steady state conditions in the main process variables in spite of changes in the energy source (solar radiation), thus demanding adequate control systems to achieve desired performance [9].

25 There are a few works in the literature related with control and modeling of SMD processes. In [10], a review of theoretical models was carried out with a description of the main variables involved in the MD process. A mathematical model was developed in [11], in order to simulate the daily production of a solar vacuum membrane distillation unit. In [12] steady-state simulations, using a wide range of operating conditions, were carried out for a direct contact membrane distillation system. A double loop optimization problem was expressed in MATLAB to solve the nonlinear equations.

From an automatic control point of view, the first work published [13], implemented and tested two temperature control loops using PI controllers in a model

35 of a SMD system. [14, 15] also proposed a dynamic mathematical model of a SMD facility to test a control system based on PI and on/off controllers aimed at temperature regulation. A very interesting control approach was presented in [16], where a control strategy based on a neural network optimization for a SMD unit was developed and experimentally tested. The neural network model of the 40 system was employed to identify a range for the feed flow rate, in which optimal operating conditions can be obtained. A control system was implemented to maximize distillate production under variable operating conditions. Besides, a feedforward $(\mathrm{FF})$ controller was used in order to reject irradiance disturbances according to the ideas of [17, 18, 19, 20, 21. The first work which deals with

45 a reference governor for this kind of facilities is [22], where a feedback control system and a reference governor were developed for keeping a desired difference temperature between both sides of the membrane.

In this work a complete feedback control architecture is proposed for an ${ }_{50}$ experimental solar powered membrane distillation facility. The use of the developed control scheme which improves the operability and dispatchability of this solar distillation technology could mean a relevant advance for commercial purposes. Thus, a full development of preliminary designs presented in 9 has been carried out and tested under real operating conditions. The proposed 55 control strategy is complemented with a reference governor which allows us to fix suitable operating temperatures in the heat generation circuit to maintain the desired temperature conditions at the entrance of the membrane module. Additional objectives have been the reduction of both operating costs and nonrenewable energy usage by optimizing the solar energy use. Dynamic models of 60 the main variables involved in the process are presented as well as the control 
system design. Simulation and experimental tests of the control system are also included to evaluate its performance.

\section{SMD system}

\subsection{MD technology}

${ }_{65} \mathrm{MD}$ is a thermally driven process in which a hydrophobic micro-porous membrane is used to accomplish the separation of volatile and non-volatile molecules. As result of the difference vapour pressure at the two membrane sides, achieved by a difference in temperature, volatile molecules are evaporated and pass through the membrane, whereas non-volatile components are rejected.

70 The evaporation process allows this technology to treat solutions with high salt concentration rejecting almost all the non-volatile components to produce high quality distillate. MD systems can be classified in several configuration according to the vapour pressure difference across the membrane [23], being Air-Gap Membrane Distillation (AGMD), the one used in this paper, one of the most 75 employed.

\subsection{Test-bed facility}

The test bed facility (see Fig. 1(a)) used in this work is located at PSA and it comprises a MD module powered by heat generation circuit that includes a solar field, an air cooler, a storage tank, a distribution system (see Fig. 2) and 80 a heat exchanger [4].

The solar field providing the required thermal energy to the distillation process consists on stationary flat-plate collectors of $2 \mathrm{~m}^{2}$ (Solaris CP1 Nova by Solaris, Spain) divided into two rows of five collectors each one. The solar field has a nominal thermal power of $7 \mathrm{~kW}$ at about $90{ }^{\circ} \mathrm{C}$, using water with antifreeze

${ }_{85}$ as heat transfer medium. An air cooler is located at the outlet of the solar field to avoid temperature excesses at the inlet of the membrane module. The solar field is connected to a thermal storage tank $(1500 \mathrm{~L})$ which can be used as energy buffer in order to work near steady state conditions when needed. As it was presented in [9], due to the hybrid nature of the facility it can be operated

90 in 14 modes. Nevertheless, only the direct connection (see Fig. 3 between the MD module and the solar field is considered in this work. From a control point of view, direct connection is the most difficult mode since the damping system (storage tank) is not used and transients are spread throughout the plant. Notice that the control algorithms developed in this paper try to be useful for

95 future development of a control algorithm able to cope with all operating modes (following the same approach in [24] for other kind of installation).

Several MD modules can be coupled to the facility by means of the distribution system (see Fig. 2), including a Liquid Gap Membrane Distillation (LGMD) configuration (built by Solar Spring), a Vacuum Membrane Distillation (VMD) module (built by Aquaver) and two AGMD configurations (built by Aquastill) 4. Each module is connected to the distribution system by means of its own heat exchanger which is used for heating cold sea water with the circulation 

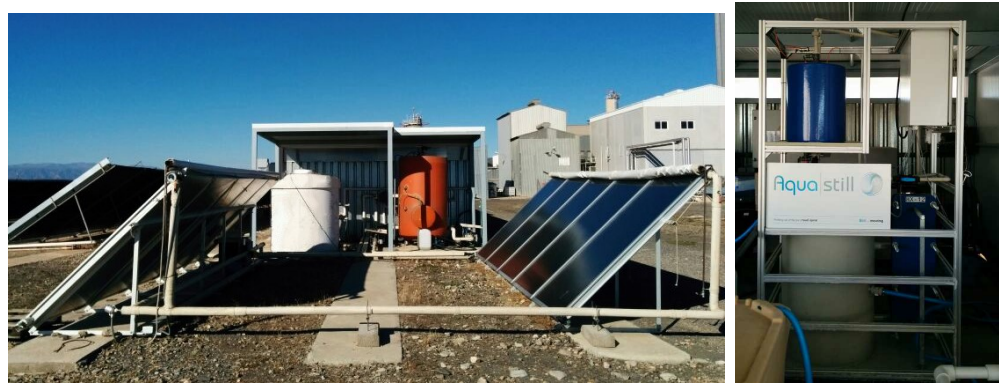

(a) SMD facility. (b) Aquastill pilot module.

Figure 1: SMD facility at PSA.

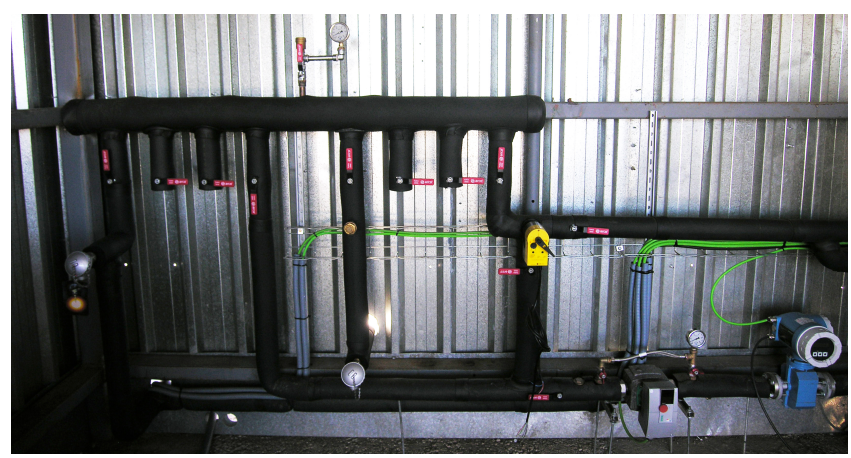

Figure 2: Distribution system.

fluid coming from the heat generation circuit. One of these Aquastill AGMD modules (see Fig. 1 (b)) is used in this work. Its heat exchanger has $1.65 \mathrm{~m}^{2}$ of exchange surface. The module has an effective area of $24 \mathrm{~m}^{2}$ with a length of 5 $\mathrm{m}$, a nominal pore size of $0.3 \mu \mathrm{m}$, porosity of $85 \%$ and membrane thickness of $76 \mu \mathrm{m}$. A productivity analysis of this module was presented by [25].

The feed tank $\left(2 \mathrm{~m}^{3}\right)$ contains an aqueous solution with a salt concentration of $35 \mathrm{~g} / \mathrm{L}$. A compressor chiller is used to keep the feed temperature constant (it is used in this pilot plant to reproduce different seawater temperatures). The temperature inside the module is limited at about $84{ }^{\circ} \mathrm{C}$ due to the thermal resistance of the membranes, whereas temperatures lower than $60^{\circ} \mathrm{C}$ produce very low distillate. The feed flow rate to the module, FT3, varies from $400 \mathrm{~L} / \mathrm{h}$ to $600 \mathrm{~L} / \mathrm{h}$.

The facility is fully monitored using the instruments detailed in Tab. 1 Besides, all the system is controlled by means of a Supervisory Control And Data Acquisition (SCADA) which monitors all the variables with a sample time of $1 \mathrm{~s}$ through an advanced data acquisition system (National Instruments). 


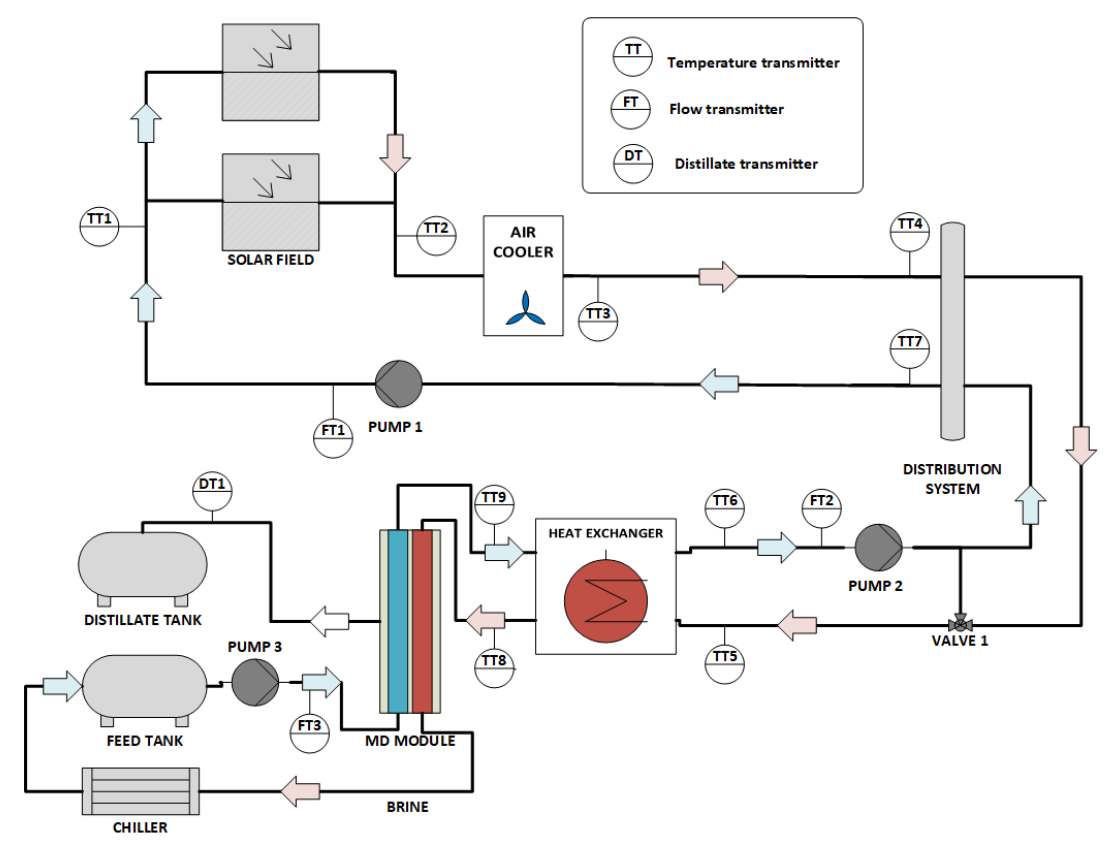

Figure 3: Schematic diagram of the active components in direct connection mode.

\begin{tabular}{lll}
\hline Variable & Manufacturer & Model \\
\hline Flow rate & Endress \& Hauser & 50P15 \\
Pressure & WIKA & S10 \\
Temperature & - & PT100 \\
Global irradiance & Kipp \& Zonen & CM6B \\
\hline
\end{tabular}

Table 1: Measurement instruments.

\section{System modeling}

To develop the control system, a dynamic model of the heat generation circuit in direct connection mode (see Fig. 33 has been developed, comprising the solar field, air cooler, distribution system, pump 1, pump 2 and valve 1 . Some of these models are based on first principles and some others have been developed from experimental data. A detailed description can be found in the

following subsections. The variables and subscripts involved are included in Appendix A.

\subsection{Models based on first principles}

\subsubsection{Solar field model}

Following the ideas presented in 20, a simplified lumped-parameters dynamical equation, based on an energy balance, is used to model the solar field 
outlet temperature, TT2. This model is developed by considering an equivalent absorber tube, characterized by an equivalent length $L_{e q}$ and an equivalent mass flow rate $\dot{m}_{e q}$, with the same behaviour as the whole solar field. Besides, this model depends on irradiance, $\mathrm{I}$, ambient temperature, $\mathrm{T}_{a}$ and inlet solar field temperature, TT1. The energy balance equation is given by:

$$
A_{s f} \cdot \rho \cdot c_{p} \cdot \frac{\partial \mathrm{TT} 2(t)}{\partial t}=\beta \cdot \mathrm{I}(t)-\frac{H}{L_{e q}} \cdot\left(\bar{T}(t)-\mathrm{T}_{a}(t)\right)-c_{p} \cdot \dot{m}_{e q} \cdot \frac{\mathrm{TT} 2(t)-\mathrm{TT} 1(t)}{L_{e q}},
$$

where:

$$
\begin{gathered}
L_{e q}=L_{a} \cdot n_{c s}, \\
\dot{m}_{e q}=\frac{\mathrm{FT} 1 \cdot \rho}{c_{f}}, \\
\bar{T}(t)=\frac{\mathrm{TT} 1(t)+\mathrm{TT} 2(t)}{2} .
\end{gathered}
$$

In this equation $\beta$ represents the collector efficiency as well as an attenuating factor, whereas $H$ represents the global thermal losses coefficient. Both 140 parameters were calibrated by using real tests with different weather conditions, providing a model which represents the solar field dynamics. The calibration method is presented in section 3.1.4. Notice that the thermal mass capacity of the solar field material has not been finally considered in Eq. 1 as its effect in the obtained mean quadratic error is almost negligible, while introducing an additional differential equation following the approach in 26 . So, the model in Eq. 1 represents a good tradeoff between performance and complexity.

\subsubsection{Heat exchanger model}

The counter-current heat exchanger available at the facility has been modeled using a simple first principles steady state model already tested in other solar systems [27], providing the performance around the selected operating point. Therefore, supposing that there is no phase change and fluid 1 (FT2 in Fig. 3) transfers energy to fluid 2 (FT3 in Fig. 3 without considering heat losses, the outlet temperature in both sides, knowing the inputs, is given by:

$$
\begin{gathered}
\mathrm{TT} 6_{\mathrm{m}}=\mathrm{TT} 5-\eta_{h e, 1} \cdot(\mathrm{TT} 5-\mathrm{TT} 9), \\
\mathrm{TT} 8_{\mathrm{m}}=\mathrm{TT} 9+\eta_{h e, 2} \cdot\left(\mathrm{TT} 5-\mathrm{TT} 6_{\mathrm{m}}\right),
\end{gathered}
$$

155 where:

$$
\begin{gathered}
\eta_{h e, 1}=\frac{1-e^{\theta_{h e}}}{1-\frac{\dot{m}_{1} \cdot c_{p, 1}}{\dot{m}_{2} \cdot c_{p, 2}} e_{h e}^{\theta_{h e}}} \\
\eta_{h e, 2}=\frac{\dot{m}_{1} \cdot c_{p, 1}}{\dot{m}_{2} \cdot c_{p, 2}} \\
\theta_{h e}=\alpha_{h e} \cdot A_{h e} \cdot\left(\frac{1}{\dot{m}_{1} \cdot c_{p, 1}}-\frac{1}{\dot{m}_{2} \cdot c_{p, 2}}\right) .
\end{gathered}
$$


Three temperature ranges are used inside the module (TT8): 60, 70 and $80{ }^{\circ} \mathrm{C}$, using three flow rates (FT3) in each range: 400, 500 and $600 \mathrm{~L} / \mathrm{h}$. Hence, the parameter $\alpha_{h e}$ has been calibrated to these operating points and interpolated by polynomial approaches. This model has been also calibrated following the calibration method presented in section 3.1.4.

\subsubsection{Distribution system and three-way mixing valve}

The distribution system and the mix produced in valve 1 can be modeled by means of static energy balances. Taking into account that the fluid is the same throughout the circuit and that FT1 must be higher than FT2, the equations are:

$$
\begin{gathered}
\mathrm{TT} 5 \cdot \mathrm{FT} 2=\mathrm{TT} 4 \cdot \gamma \cdot \mathrm{FT} 2+\mathrm{TT} 6 \cdot(1-\gamma) \cdot \mathrm{FT} 2, \\
\mathrm{TT} 7=\frac{\mathrm{TT} 4 \cdot(\mathrm{FT} 1-\gamma \cdot \mathrm{FT} 2)+\mathrm{TT} 6 \cdot \gamma \cdot \mathrm{FT} 2}{\mathrm{FT} 1},
\end{gathered}
$$

where $\gamma$ is the aperture of valve 1 . Notice that the nonlinear static characteristic curve of the valve relating the position of the valve stem with the fraction of

170 the mass flow $\gamma$ has been modeled by a piecewise linear approximation and thus the inverse of this approximation has been used to linearize its behavior as done in 28. Moreover, a low pass filter has been added to the output of equations (10) and 11 with a time constant of 5 and $7 \mathrm{~s}$ respectively to fit the simulation curves to the observed step-response tests.

\subsubsection{Model calibration and validation}

Both solar field and heat exchanger models are classified as gray box models since there is a first-principles based model structure and some unknown parameters. Calibration of the model by identifying these unknown parameters has been done using the Mean Squared Error (MSE) as objective function (using as error the difference between the outputs calculated by the model and the real measurements):

$$
M S E=\frac{1}{N} \sum_{k=1}^{N}(\hat{Y}(k)-Y(k))^{2},
$$

where $\hat{Y}(k)$ is the value calculated by the model in the discrete time instant $k$ and $Y(k)$ is the real measurements at the same instant. $N$ is the number of measurements used for calibration purposes.

For the solar field model, that is linear in the parameters, the typical leastsquares identification method has been used. In the nonlinear case (heat exchanger model), a combination of global and local optimization algorithms has been applied. Genetic Algorithm (GA) has been chosen as global search due to its random nature, and an interior point method as local search algorithm.

The values obtained for solar field model parameters, $\beta$ and $H$, are $0.11 \mathrm{~m}$ and $5.88 \mathrm{~J} / \mathrm{s} \cdot \mathrm{K}$ respectively. In this case, 15 days with different environmental conditions have been used for calibration purposes, whereas 5 days have been 

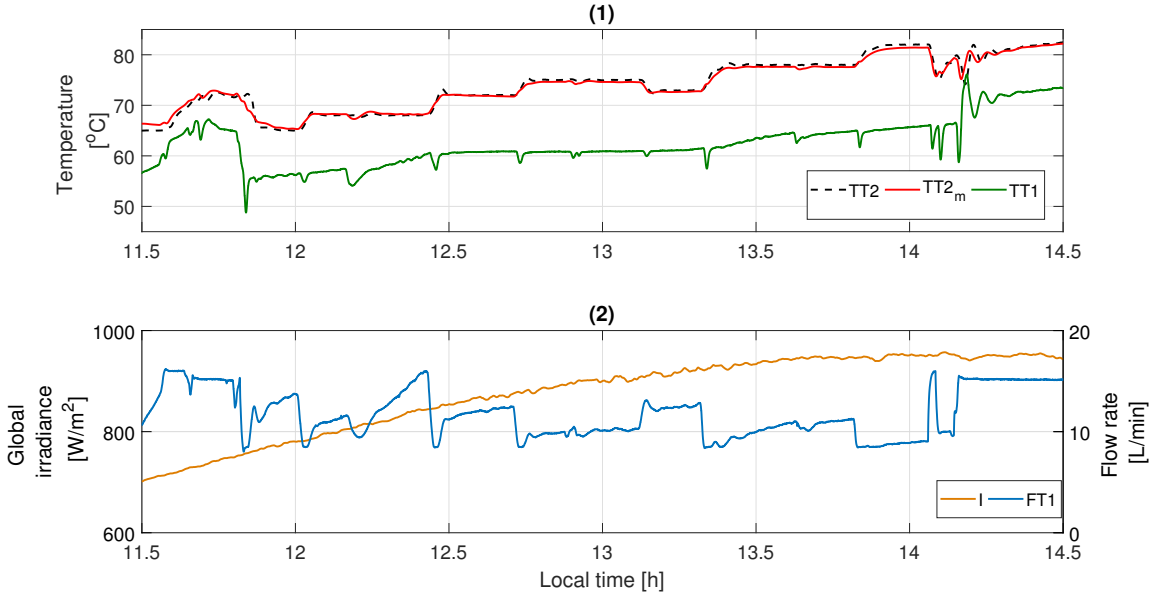

Figure 4: Solar field model validation. (1) Outlet solar field temperature (TT2), model output $(\mathrm{TT} 2 \mathrm{~m})$ and inlet solar field temperature (TT1) and (2) solar field water flow rate (FT1) and global irradiance (I).
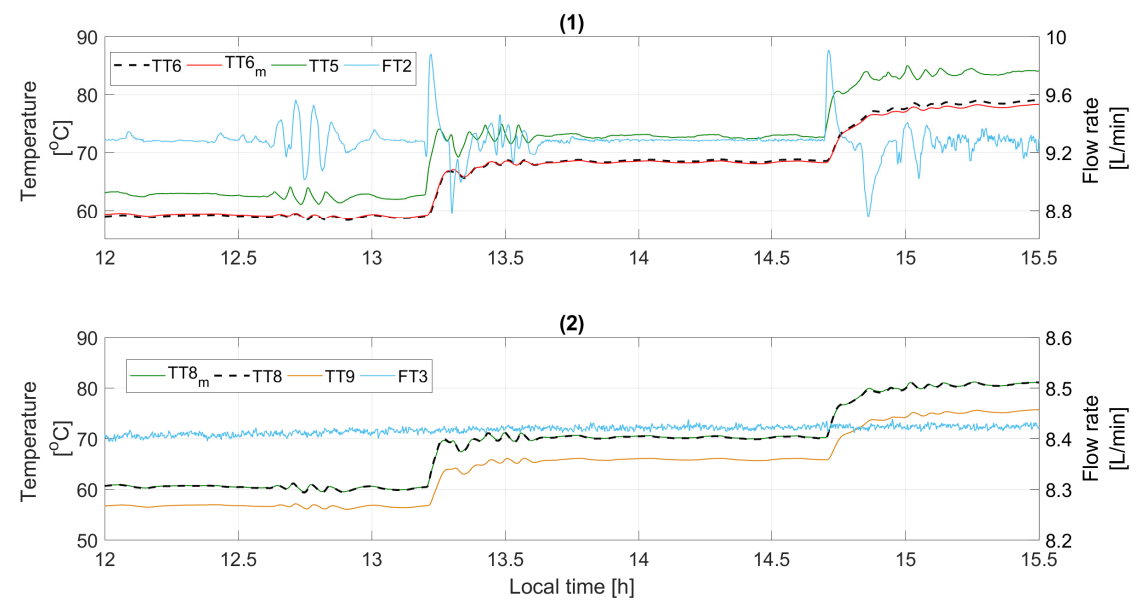

Figure 5: Heat exchanger model validation using a day with oscillations caused by the chiller operation. (1) Water outlet temperature leaving the hot side of the heat exchanger (TT6), model output (TT6m), inlet temperature to the hot side of the heat exchanger (TT5) and heat exchanger water flow rate (FT3) and (2) water outlet temperature leaving the cold side of the heat exchanger (TT8), model output $\left(\mathrm{TT} 8_{\mathrm{m}}\right)$, inlet temperature to the cold side of the heat exchanger (TT9) and MD water flow rate (FT3). 


\begin{tabular}{ccc}
\hline Temperature $\left[{ }^{\circ} \mathbf{C}\right]$ & Flow rate $[\mathbf{L} / \mathbf{h}]$ & $\alpha_{h e}\left[\mathbf{W} / \mathbf{m}^{2} \cdot \mathbf{K}\right]$ \\
\hline \multirow{2}{*}{60} & 400 & 480.29 \\
& 500 & 582.81 \\
& 600 & 754.05 \\
\hline \multirow{2}{*}{70} & 400 & 530.22 \\
& 500 & 689.30 \\
\multirow{2}{*}{80} & 600 & 857.13 \\
& 400 & 476.44 \\
& 500 & 593.40 \\
& 600 & 670.78 \\
\hline
\end{tabular}

Table 2: $\alpha_{h e}$ values.

considered for validation. Fig. 4 shows a solar field model illustrative validation tests. The mean error is $1.05{ }^{\circ} \mathrm{C}$, while the maximum error is $2.85{ }^{\circ} \mathrm{C}$.

195 nonlinear calibration method. The value of the parameter $\alpha_{h e}$ is presented in Tab. 2 and a representative validation result in Fig. 5 For this model, 5 days with variable operation conditions have been considered for calibration and 2 for validation. fit real step response data. The representative time constant is $40 \mathrm{~s}$ and the time delay is $23 \mathrm{~s}$ for $\mathrm{TT} 6_{\mathrm{m}}$ while the time constant is $20 \mathrm{~s}$ and the time delay is $15 \mathrm{~s}$ for $\mathrm{TT} 8_{\mathrm{m}}$. In this case, the mean error is $0.445^{\circ} \mathrm{C}$, being the maximum error $0.895{ }^{\circ} \mathrm{C}$ for TT6 whereas the mean error for TT8 is $0.36{ }^{\circ} \mathrm{C}$ and the maximum 205 error is $0.82^{\circ} \mathrm{C}$. If the heat transfer coefficient is considered constant $\left(\alpha_{h e}=\right.$ $\left.670.78 \mathrm{~W} /\left(\mathrm{m}^{2} \cdot \mathrm{K}\right)\right)$ in the full operating range, the mean error for TT6 would be $0.69{ }^{\circ} \mathrm{C}$, being the maximum error $1.15{ }^{\circ} \mathrm{C}$ whereas the mean error for TT 8 would be $0.51{ }^{\circ} \mathrm{C}$ and the maximum error $1.06{ }^{\circ} \mathrm{C}$.

\subsection{Models based on experimental data}

210

In addition to the model based on first principles, transfer functions experimentally obtained have been considered to model the relation between the main variables involved in the process to the controlled variables. Open-loop tests have been performed, introducing typical step changes and making use of the State-Variable Filters (SVF) approach and the Generalized Poisson Moment Functions (GPMF) approach 29, to estimate the parameters of the corresponding first order plus dead time (FOPDT) transfer functions. The metric function used to evaluate the percentage of the response reproduced by the model is the Normalized Root Mean Square Error (NRMSE, see MSE definition):

$$
\operatorname{NRMSE}[\%]=\sqrt{\frac{\sum_{k=1}^{N}(\hat{Y}(k)-Y(k))^{2}}{\sum_{k=1}^{N}(Y(k))^{2}}} .
$$


Table 3 summarizes the obtained FOPDT transfer functions in the form $G(s)=Y(s) / U(s)=k \cdot e^{-t_{d} s} /(\tau \cdot s+1)$, where $k$ is the static gain, $\tau$ is the representative time constant and $t_{d}$ the time delay.

Firstly, to characterize the pumps used in the control system (Pump 1 and Pump 2 in Fig. 3), step changes of $20 \%$ in its variable frequency drive were applied each 3 minutes to obtain $G_{1}(s)$ and $G_{2}(s)$ respectively (see Tab. 3).

225 In the same way, the relationship between FT1 and the outlet solar field temperature TT2 $\left(G_{3}(s)\right)$ has been determined by introducing step changes in the flow rate FT1. It was accomplished under quasi-steady conditions in the inlet temperature of the solar field TT1, and around solar midday when the global irradiance is almost constant. The effect of the air cooler has been also modeled 230 through reaction curve method to allow us obtaining $G_{4}(s)$, relating TT3 with the frequency drive of the air cooler. As in the previous case, this test was carried out around solar midday with quasi-steady conditions in TT1. Finally, the relation between valve 1 and TT5 was obtained $\left(G_{5}(s)\right)$ by means of several open loop steps of different values with quasi-steady conditions in TT4. Apart from this relation, the linear range of the valve was identified between $40-75 \%$.

\begin{tabular}{ccccccc}
\hline$G(s)$ & $Y(s)$ & $U(s)$ & $k$ & $\tau[\mathrm{s}]$ & $t_{d}[\mathrm{~s}]$ & NRMSE [\%] \\
\hline \hline$G_{1}(s)$ & $\mathrm{FT} 1(s)$ & $\mathrm{F}_{\mathrm{P} 1}(s)$ & 0.2344 & 5 & 1 & 96.7 \\
\hline$G_{2}(s)$ & $\mathrm{FT} 2(s)$ & $\mathrm{F}_{\mathrm{P} 2}(s)$ & 0.1345 & 8.03 & 3 & 97.2 \\
\hline$G_{3}(s)$ & $\mathrm{TT} 2(s)$ & $\mathrm{FT} 1(s)$ & -1.37 & 66.62 & 16 & 95.2 \\
\hline$G_{4}(s)$ & $\mathrm{TT} 3(s)$ & $\mathrm{F}_{a c}(s)$ & -0.1087 & 27.48 & 20 & 96.5 \\
\hline$G_{5}(s)$ & $\mathrm{TT} 5(s)$ & $\mathrm{F}_{\mathrm{V} 1}(s)$ & 0.1502 & 14.3 & 10 & 86.2 \\
\hline
\end{tabular}

Table 3: Transfer functions obtained from experimental data.

\subsection{Complete model of the heat generation circuit in the direct connection mode}

Using the equations shown in section 3.1 and the FOPDT models presented in Tab. 3. a complete model of the heat generation circuit in the direct connection mode has been developed in Simulink (MATLAB). In addition to the 240 models shown in section 3.1 and 3.2, transport dead times have been added to model delays caused by the interconnection of the pipes and the sensor position. These transport delays have been observed from field data and they do not change significantly with the operating ranges. The dead time values are presented in Tab. 4. Fig. 6 shows the comparison between real measures and

245 the model outputs. The inputs used are: pump 1, pump 2, air cooler, valve 1 , global irradiance, FT3 and TT9.

\begin{tabular}{cc}
\hline Pipe section & Dead time $[\mathbf{s}]$ \\
\hline TT3-TT4 & 35 \\
TT7-TT1 & 65 \\
\hline
\end{tabular}

Table 4: Dead time values. 

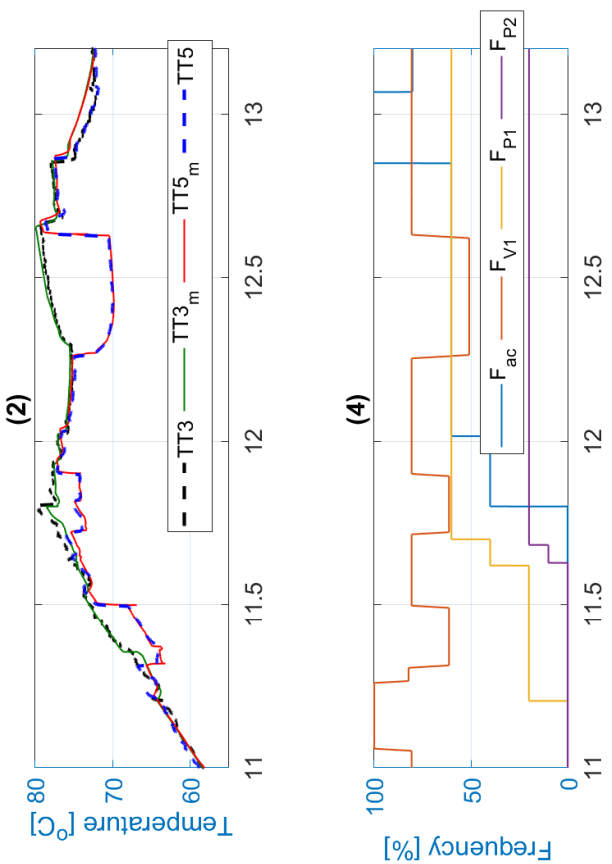

[\%] אouənbəגঘ



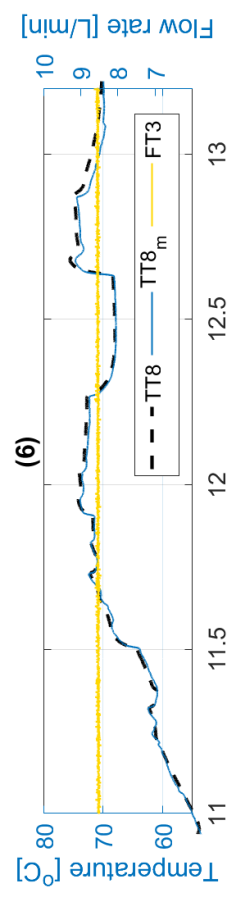

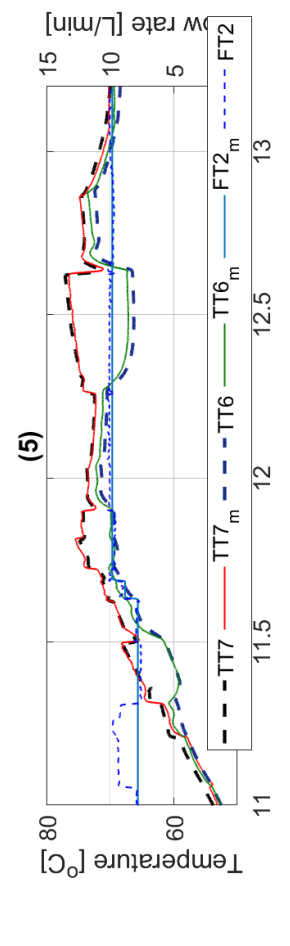

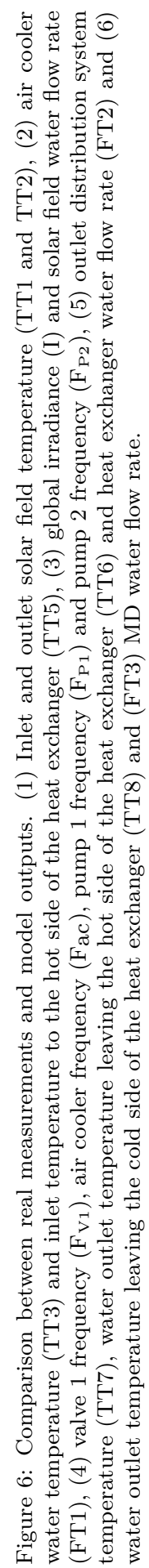




\section{Control system}

The main objective of the control system is to maintain a desired operating temperature at the inlet of the MD module. To this purpose, four direct control loops (see Fig. 7) and a reference governor are proposed. The linear models developed in section 3.2 have been used to design the corresponding control laws. Furthermore, the control scheme includes antiwindup mechanisms to take into account saturation problems. It should be mentioned that, this control architecture is proposed rather than other techniques such as multivariable control with decoupling, since it can be used in all the operation modes included in 9 .

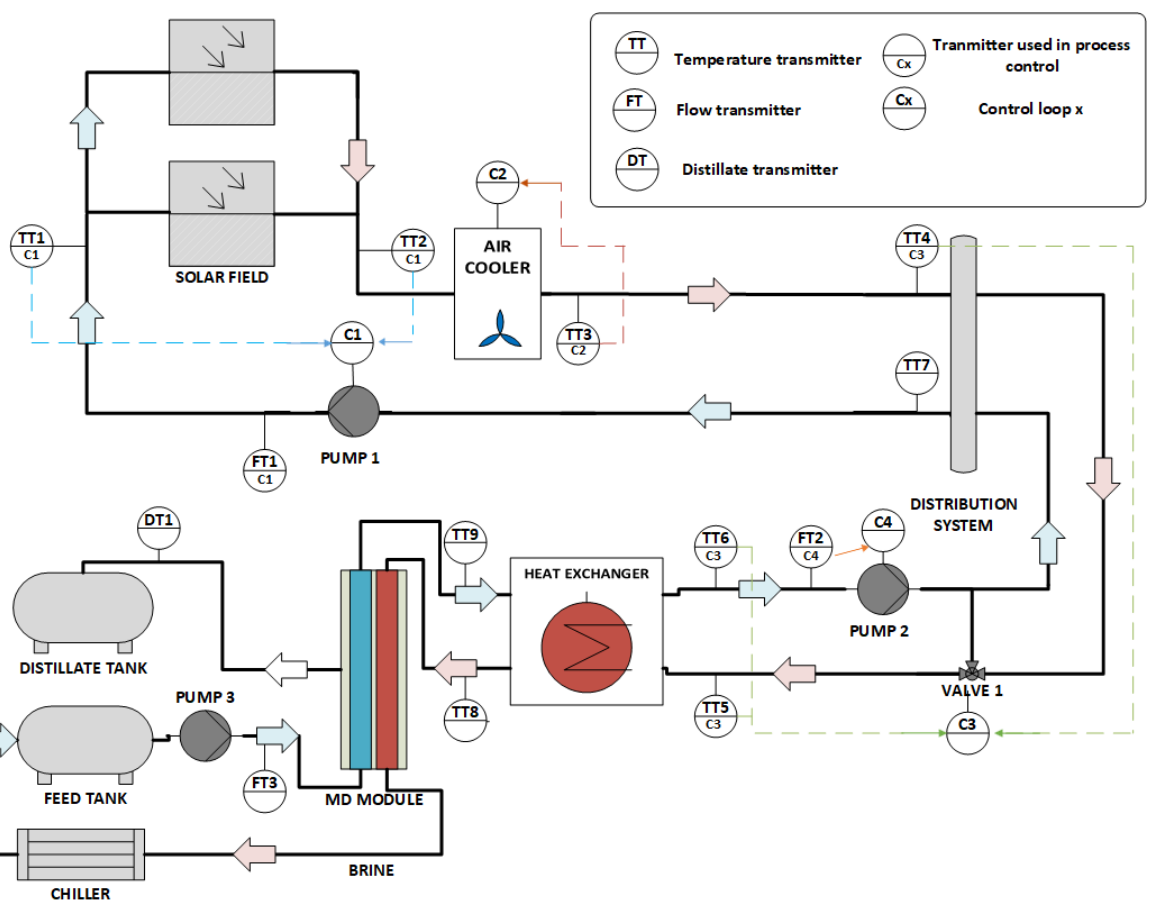

Figure 7: Schematic diagram of the active components in direct connection mode with control loops.

\subsection{Loop 1. Solar field}

The transfer functions obtained in section 3.2 have been used for control design purposes. A cascade control loop with two PI controllers $(P I(s)=$ $K_{p}\left(1+1 /\left(T_{i} \cdot s\right)\right)$ has been designed to control the outlet solar field temperature TT2. The slave control is in charge of providing the desired water flow rate FT1 by acting on the variable frequency drive of pump 1 and the outer loop calculates the required water flow rate FT1 which allows to obtain the desired outlet solar 
field temperature TT2. The cascade control loop has been configured with the following parameters:

- Slave PI: $K_{p}=2.84 \% \cdot \mathrm{min} / \mathrm{L}$ and $T_{i}=0.082 \mathrm{~min}$ (AMIGO method, [28]).

- Outer PI: $K_{p}=-0.42 \mathrm{~L} / \mathrm{min} /{ }^{\circ} \mathrm{C}$ and $T_{i}=1.21 \mathrm{~min}$ (SIMC method, 30]).

Due to the fact that the system is subjected to strong disturbances caused by solar irradiance I and inlet solar field temperature TT1, a FF controller has been included in this loop. This FF is obtained using a static version of the solar 270 field model presented in section 3.1.1 and it provides the nominal operating flow rate $\left(\mathrm{FT}_{\mathrm{FF}}\right)$ taking into account the operating conditions. The static equation making $\mathrm{TT} 2=\mathrm{TT} 2_{\mathrm{SP}}$ in Eq. 1 is given by:

$$
\begin{gathered}
\mathrm{FT} 1_{\mathrm{FF}}=\left[\frac{\beta \cdot L_{e q}}{c_{p} \cdot\left(\mathrm{TT} 2_{\mathrm{SP}}(t)-\mathrm{TT} 1(t)\right)} \cdot \mathrm{I}(t)-\frac{H}{c_{p}} \cdot \frac{\left(\bar{T}(t)-\mathrm{T}_{a}(t)\right)}{\left(\mathrm{TT} 2_{\mathrm{SP}}(t)-\mathrm{TT} 1(t)\right)}\right] \cdot \frac{c_{f}}{\rho}, \\
\bar{T}(t)=\frac{\mathrm{TT} 1(t)+\mathrm{TT} 2_{\mathrm{SP}}(t)}{2} .
\end{gathered}
$$

The nomenclature associated to the equation is presented in Appendix A. A low pass filter (LPF) has been added to this static equation with a representa275 tive time constant of $75 \mathrm{~s}$ to achieve a better dynamical and smooth response. Finally, a low pass filter of $60 \mathrm{~s}$ has been included in the reference signal to find a good tradeoff between reference tracking and disturbances rejection and to reduce overshoots against setpoint step changes. Fig. 8 shows the control scheme.

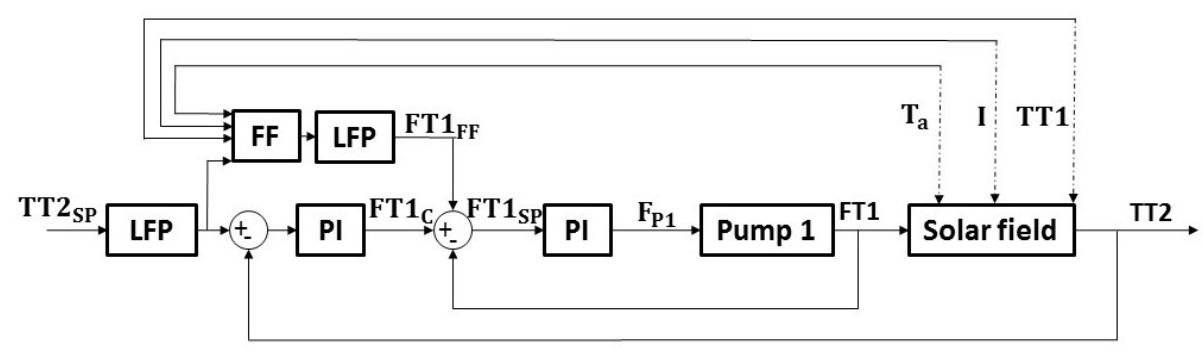

Figure 8: Solar field control scheme.

\subsection{Loop 2. Air cooler}

This loop is also focused on controlling the outlet solar field temperature and it acts when TT2 is higher than desired outlet solar field temperature, mainly due to flow saturation. Fig. 9 shows the control scheme. The PI controller has been configured with $K_{p}=-7.48 \% \cdot \mathrm{min} /{ }^{\circ} \mathrm{C}$ and $T_{i}=0.233$ min (Improved SIMC method, [31]), using the linear model presented in Tab. 3 


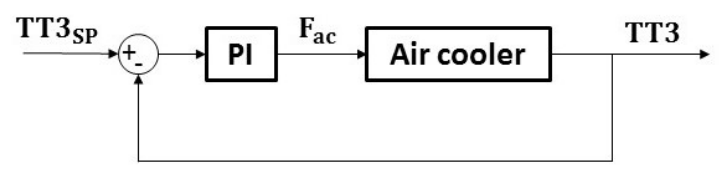

Figure 9: Air cooler control scheme.

\subsection{Loop 3. Valve 1 control loop}

Although in direct mode the inlet heat exchanger temperature TT5 could be controlled with loop 2 described previously (if valve 1 is fully open), a temperature control loop using valve 1 is considered to improve the setpoint tracking and to reject disturbances coming from the distribution system (TT4). To this purpose, a PI controller with a FF is developed. Based on the steady-state energy balance obtained from Eq. 10, the FF has been designed such as:

$$
\mathrm{F}_{\mathrm{V} 1, \mathrm{FF}}(\%)=\frac{\mathrm{TT} 5_{\mathrm{SP}}-\mathrm{TT} 6}{\mathrm{TT} 4-\mathrm{TT} 6} \cdot 100 .
$$

In order to achieve a better dynamical response and smooth response, a low pass filter has been added to the $\mathrm{FF}$ with a representative time constant of 65 s. Fig. 10 shows the control scheme. The parameters of the PI controller are: $K_{p}=2.22 \% \cdot \min /{ }^{\circ} \mathrm{C}$ and $T_{i}=0.5 \mathrm{~min}$ (Improved SIMC method, [31]), using the linear model in Tab. 3

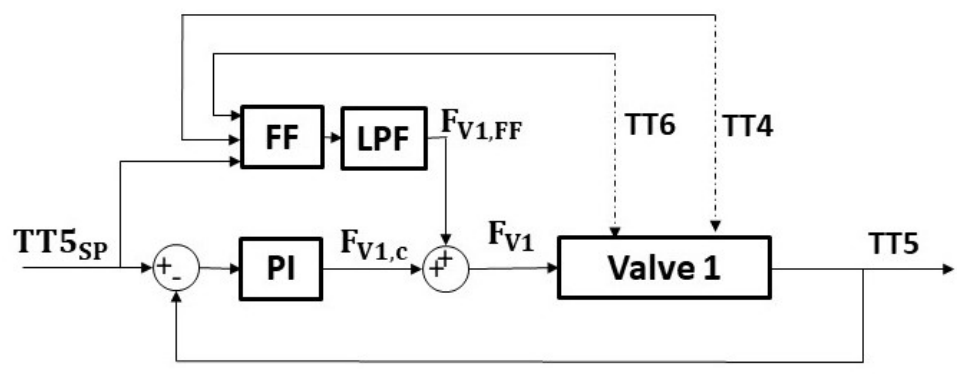

Figure 10: Valve 1 control scheme.

\subsection{Loop 4. Heat exchanger water flow rate}

Although the control system is aimed at temperature control purposes, variations in valve 1 , cause variations in the flow rate and therefore in the temperature, so it is necessary to fix the water flow rate FT2 by means of a controller. Besides, by fixing FT2 with the same value as FT3, the maximum heat transfer is achieved in the heat exchanger. However, it should be taken into account that FT2 cannot be higher than FT1, due to the fact that the fluid coming from the solar field and the fluid coming from the heat exchanger would be mixed in the hotter side of the distribution system. A PI controller is designed 
with a setpoint limiter which checks if FT2 setpoint is less than FT1, which varies to maintain the outlet solar field temperature, loop 1. The PI controller has been configured with $K_{p}=4.12 \% \cdot \mathrm{min} / \mathrm{L}$ and $T_{i}=0.1505 \mathrm{~min}$ (Improved SIMC method, 31), using the transfer function presented in Tab. 3 Fig. 11 shows the control scheme.



Figure 11: Heat exchanger water flow rate control scheme.

\subsection{Reference governor}

The proposed temperature control scheme with the reference governor is shown in Fig. 12 The heat exchanger model presented in section 3.1.2 is used to calculate suitable setpoints for the direct control system, helping to obtain the desired temperature at the inlet of the MD module (TT8).

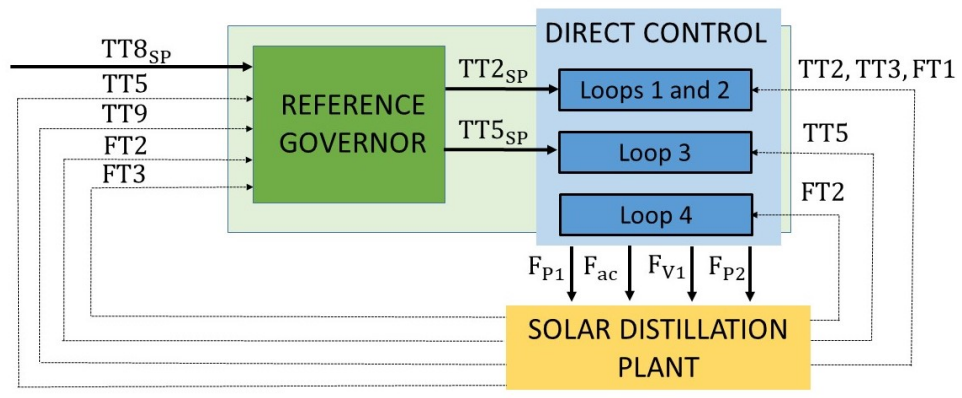

Figure 12: Reference governor scheme.

The equations implemented in the reference governor are the following ones:

$$
\begin{aligned}
\mathrm{TT} 6_{\mathrm{m}} & =\mathrm{TT} 5-\eta_{h e, 1} \cdot(\mathrm{TT} 5-\mathrm{TT} 9), \\
\mathrm{TT} 5_{\mathrm{SP}} & =\frac{\mathrm{TT} 8_{\mathrm{SP}}-\mathrm{TT} 9+\eta_{h e, 2} \cdot \mathrm{TT} 6_{\mathrm{m}}}{\eta_{h e, 2}} .
\end{aligned}
$$

Thus, Eq. 18 gives $\mathrm{TT} 5_{\mathrm{SP}}$ and the setpoint for loops 1 and 2 is $\mathrm{TT} 5_{\mathrm{SP}}+\triangle \mathrm{T}$. This $\triangle \mathrm{T}$ must be characterized for each module in order to balance the corresponding energy consumption. The nominal value characterized for Aquastill $24 \mathrm{~m}^{2}$-module, based on experience, is $4{ }^{\circ} \mathrm{C}$. Besides, this $\triangle \mathrm{T}$ maintains the temperature of the solar field higher than the desired temperature at the inlet of the heat exchanger, allowing valve 1 acting in its linear range. 
It is important to emphasize that this system in direct mode requires smooth setpoint changes rather than step ones to avoid oscillations. Therefore, a LPF has been added to each setpoint. The representative time constants for $\mathrm{TT} 2_{\mathrm{SP}}$ and $\mathrm{TT} 5_{\mathrm{SP}}$ are 85 and 75 s respectively.

\section{Simulation tests}

This section shows two simulation tests carried out in order to analyse the performance of the control system under two different weather profiles, using data from PSA on 21 and 25 September 2016. The model developed in section 3 has been used in this test to simulate the plant behaviour. Notice that TT9 is an input to the control system (see Fig. 12), so this temperature is also

335 required to test the performance. Since TT9 depends on operating conditions (sea water flow rate and temperature and flow rate and temperature of the water coming from the heat exchanger) and the three first inputs are assumed constant $\left(\mathrm{FT} 3=500 \mathrm{~L} / \mathrm{h}\right.$, sea water temperature $=20{ }^{\circ} \mathrm{C}$, and $\left.\mathrm{FT} 2=\mathrm{FT} 3\right)$ in the simulations carried out, only temperature TT8 must be considered to simulate variations in TT9 and test the control system. In the operational range employed in TT8 $\left(60-80{ }^{\circ} \mathrm{C}\right)$, the temperature difference observed during the experimental campaign performed to model the plant varies between 3.5 and $4.5^{\circ} \mathrm{C}$, so that, a fixed value of $4{ }^{\circ} \mathrm{C}$ has been used in the simulation tests.

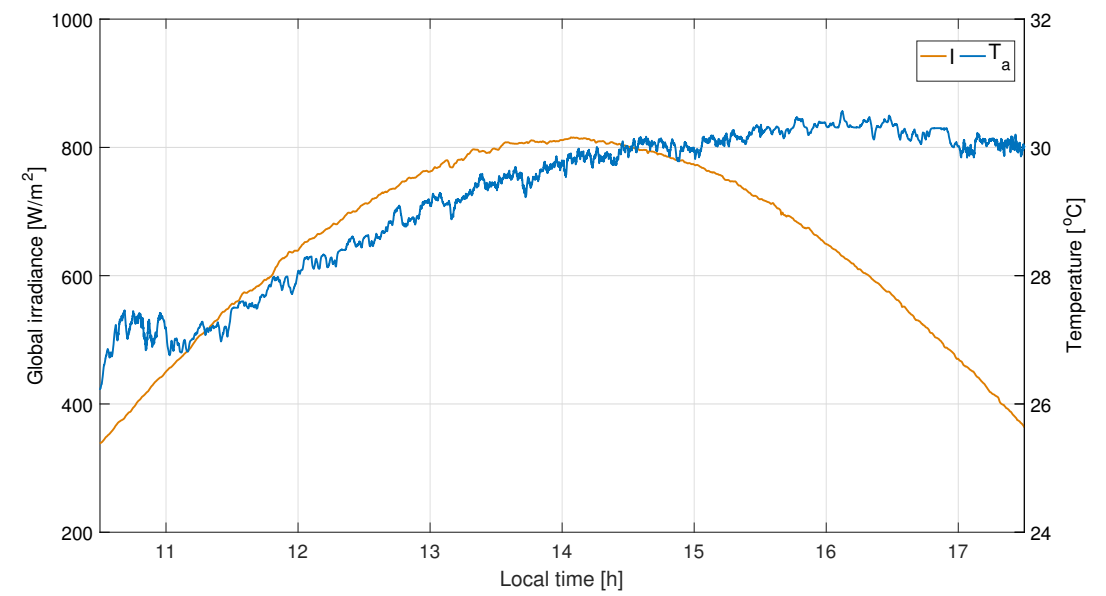

Figure 13: Meteorological inputs for the simulation test in a sunny day. Global irradiance (I) and ambient temperature $\left(\mathrm{T}_{a}\right)$.

\subsection{Sunny Day}

345

Fig. 13 shows the environmental conditions used for this simulation test. At the beginning, the temperature at the inlet of the MD module is higher than the 

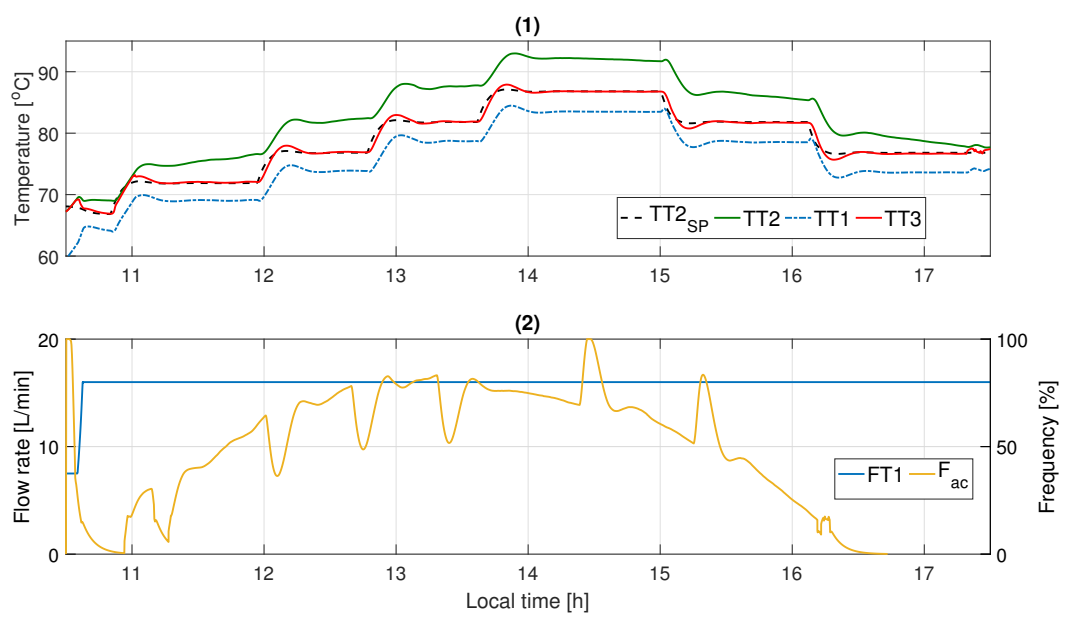

Figure 14: Simulation results of loops 1 and 2 in a sunny day. (1) Reference (TT2 $2_{\mathrm{SP}}$ ), outlet solar field temperature (TT2), inlet solar field temperature (TT1) and water air cooler temperature (TT3) and (2) solar field flow rate $(\mathrm{FT} 1)$ and air cooler frequency $\left(\mathrm{F}_{a c}\right)$.
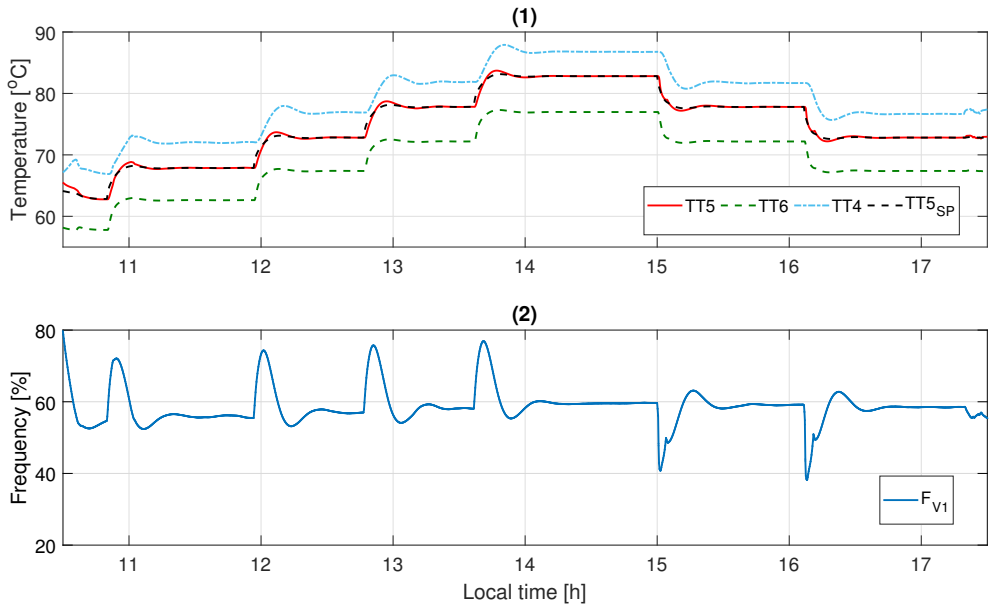

Figure 15: Simulation results of loops 3 in a sunny day. (1) Inlet temperature to the hot side of the heat exchanger (TT5), water outlet temperature leaving the hot side of the heat exchanger (TT6), inlet distribution system temperature (TT4) and reference ( $\left.\mathrm{TT} 5_{\mathrm{SP}}\right)$ and $(2)$ valve 1 frequency $\left(\mathrm{F}_{\mathrm{V} 1}\right)$.

setpoint fixed, $60{ }^{\circ} \mathrm{C}$ (see Fig. 16). Due to this fact the reference governor decreases the setpoints of each direct control loop (see Fig. 14 and 15) on a smooth way, allowing to reach the reference. Then, positive step changes of $5{ }^{\circ} \mathrm{C}$ are 


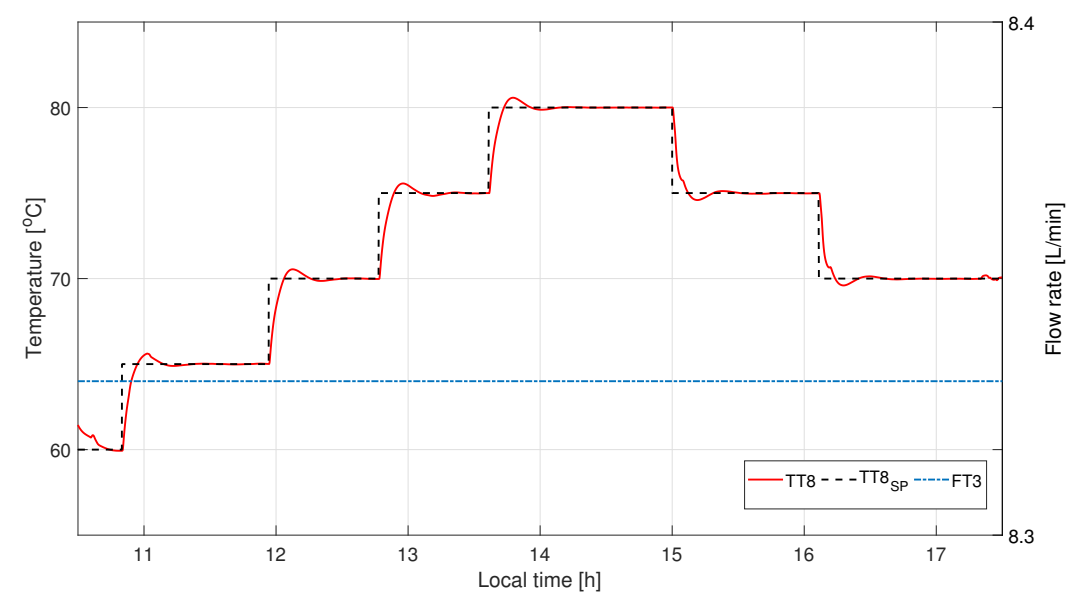

Figure 16: Simulation results at the inlet of the MD module in a sunny day. Water outlet temperature leaving the cold side of the heat exchanger (TT8), reference (TT8 $\left.8_{\mathrm{SP}}\right)$ and $\mathrm{MD}$ module water flow rate (FT3).

introduced in $\mathrm{TT}_{\mathrm{SP}}$ at times 10.83, 11.94, 12.78 and $13.61 \mathrm{~h}$. In Fig. 14 and 15 it can be observed how the setpoints of each loop are increased by the reference governor to reach the desired temperatures at the inlet of the MD module. The settling times in these changes are around $20 \mathrm{~min}$ and the overshoots are around 10-15\%. Notice that a tradeoff solution between overshoots and settling times has been reached with this control system configuration. Thus, better results are obtained in comparison with manual operations; settling times are 20-30 min faster and the obtained overshoots are within the allowed range defined by plant operators. At times 15 and $16.11 \mathrm{~h}$ two negative steps of $5{ }^{\circ} \mathrm{C}$ are applied at $\mathrm{TT} 8_{\mathrm{SP}}$ with similar dynamical results as the positive ones.

In this test, loop 1 is saturated all the time because of irradiance values as well as the low energy consumption of the module and solar field oversizing. Thus, the air cooler is used to control the temperature excess, as can be observed in Fig. 14 Since the references of this loop are $4{ }^{\circ} \mathrm{C}$ higher than those of loop 3, valve 1 acts in its linear range (see Fig. 15) getting an accurate control at the inlet of the heat exchanger. It is important to mention that, this fact is essential to get an adequate temperature control at the inlet of the MD module.

\subsection{Cloudy Day}

In this example, the irradiance curve shows fluctuations due to transient clouds (see Fig. 17). At the beginning, the temperature at the inlet of the MD

module is higher than the desired value (see Fig. 20), so the reference governor decreases the setpoints of the direct control system (see Fig. 18 and 19). Then, at times 12.22 and $13.89 \mathrm{~h}$, two positive steps of $5^{\circ} \mathrm{C}$ at $\mathrm{TT} 8_{\mathrm{SP}}$ are introduced. 


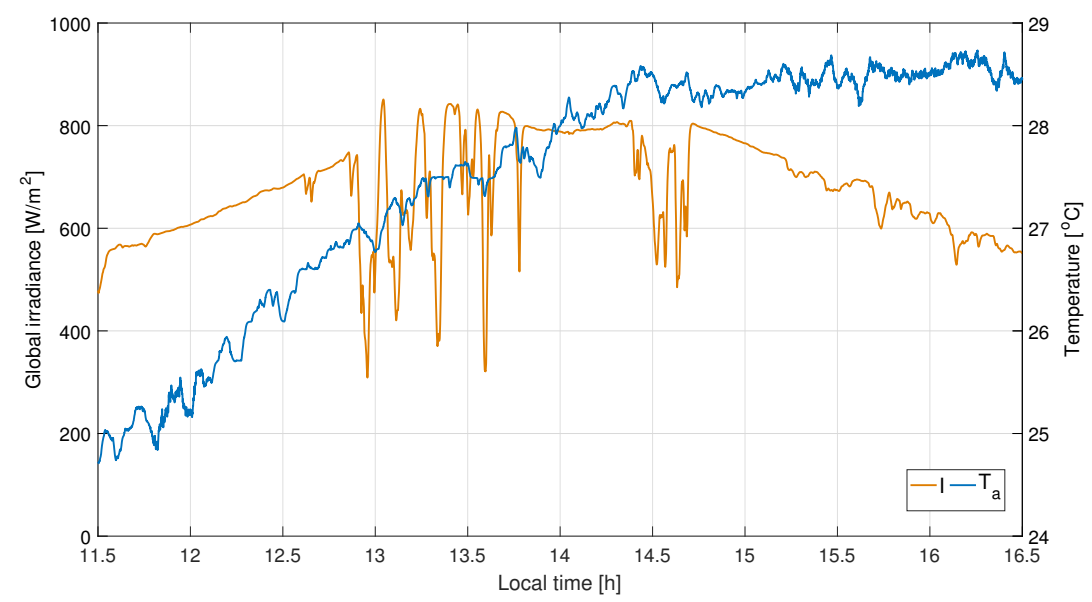

Figure 17: Meteorological inputs of the simulation test in a partly cloudy day. Global irradiance (I) and ambient temperature $\left(\mathrm{T}_{a}\right)$.
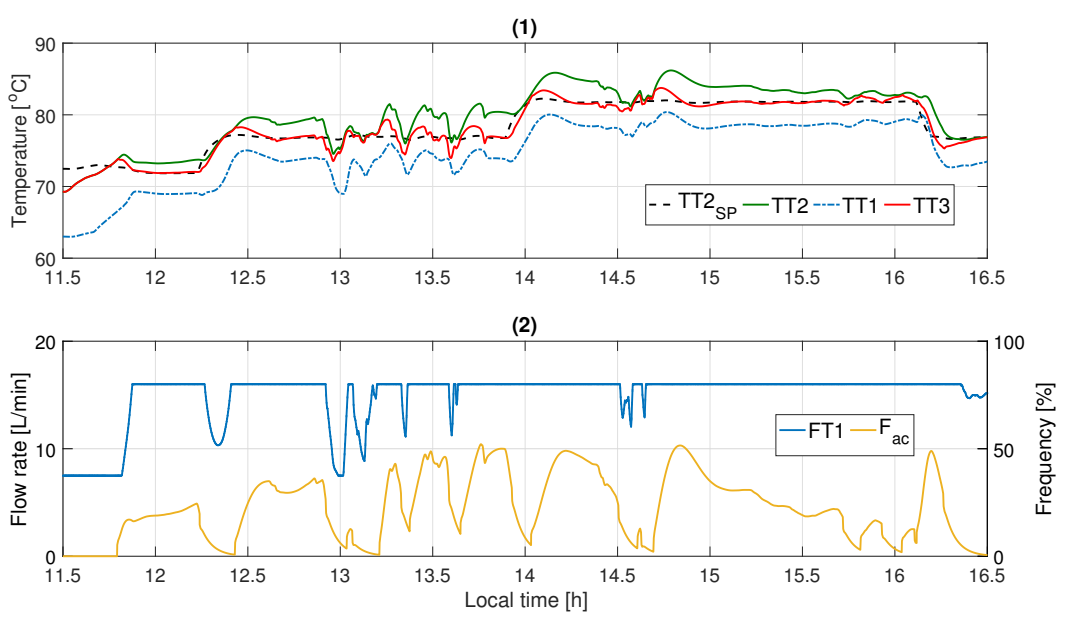

Figure 18: Simulation results of loops 1 and 2 in a partly cloudy day. (1) Reference (TT2 $2_{\mathrm{SP}}$ ), outlet solar field temperature (TT2), inlet solar field temperature (TT1) and water air cooler temperature (TT3) and (2) solar field flow rate (FT1) and air cooler frequency $\left(\mathrm{F}_{a c}\right)$.

In this case, the overshoots are around $15 \%$ and the settling times are around 25 min. It should be taken into account that in this test, the tracking errors 375 of the direct control loops are higher than in the test above, due to irradiance fluctuations. A time $16.11 \mathrm{~h}$ a negative step of $5{ }^{\circ} \mathrm{C}$ at $\mathrm{TT} 8_{\mathrm{SP}}$ is introduced with similar results. 
(1)
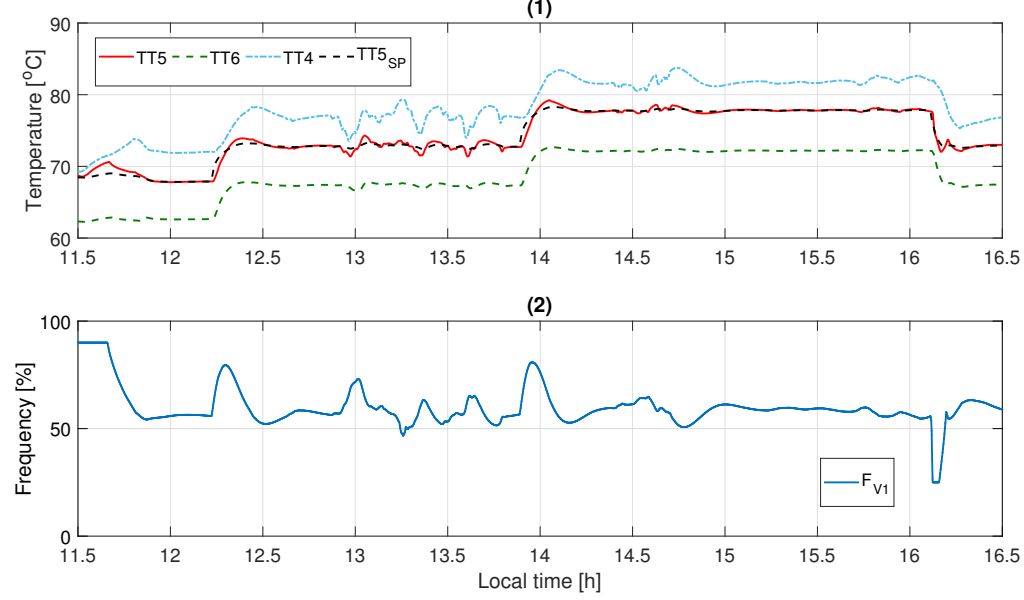

Figure 19: Simulation results of loops 3 in a partly cloudy day. (1) Inlet temperature to the hot side of the heat exchanger (TT5), water outlet temperature leaving the hot side of the heat exchanger (TT6), inlet distribution system temperature (TT4) and reference $\left(\mathrm{TT} 5_{\mathrm{SP}}\right)$ and (2) valve 1 frequency $\left(\mathrm{F}_{\mathrm{V} 1}\right)$.

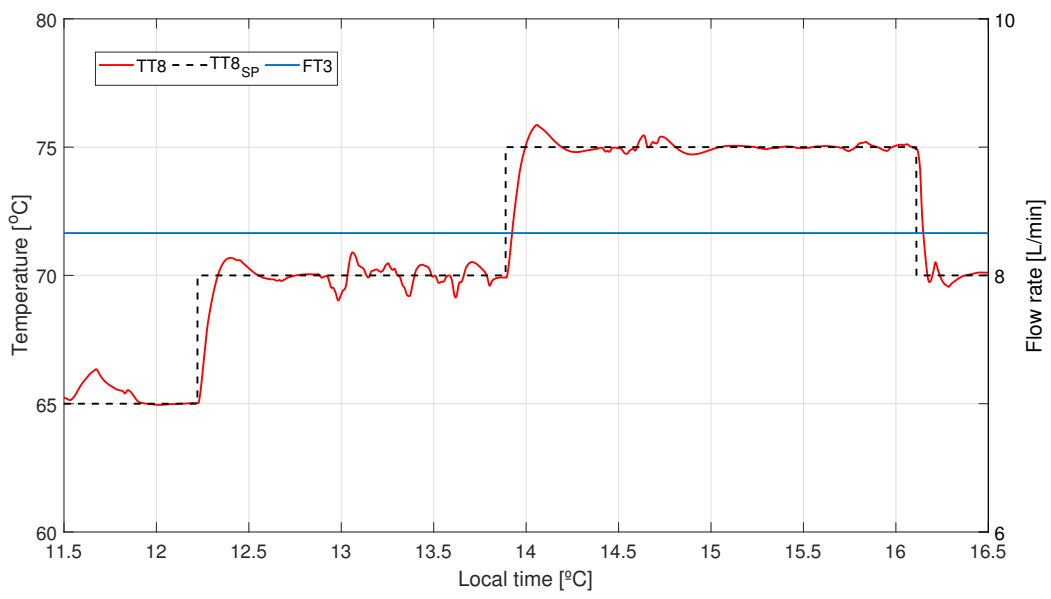

Figure 20: Simulation results at the inlet of the MD module in a partly cloudy day. Water outlet temperature leaving the cold side of the heat exchanger $(\mathrm{TT} 8)$, reference $\left(\mathrm{TT} 8_{\mathrm{SP}}\right)$ and MD module water flow rate (FT3).

Fig. 18 shows how the solar field water flow rate decreases according to the irradiance level, reducing temperature fluctuations. Besides, these fluctuations are also reduced by loop 3 as can be observed in Fig. 19 by means of the 
FF, which rejects disturbances coming from the distribution system. Finally, at the inlet of the MD module, the temperature varies in a range less than $\pm 1{ }^{\circ} \mathrm{C}$ when there are irradiance disturbances (see Fig. 17). Notice that the tracking error accepted by plant operators in a manual operation with favourable

\section{Real experimental test}

An experimental campaign has been performed in the solar distillation facility to test the proposed control strategy under different operating and weather conditions. One of these tests (on September 30th, 2016) is presented in this 390 section, clearly improving (in terms of performance indexes such as overshoot and settling times) preliminary results presented in $[9$.

Fig. 21. 22 and 23 show the experimental results. Firstly, a setpoint of $55^{\circ} \mathrm{C}$ is imposed at the inlet of the MD module and FT2 is fixed with the same value as FT3, 8.6 L/min. Since the temperature is lower than the setpoint fixed, the 22 . Once the system reaches the desired temperature, a step change of $5{ }^{\circ} \mathrm{C}$ at $\mathrm{TT} 8_{\mathrm{SP}}$ is introduced at time $12.01 \mathrm{~h}$. The setpoints for the direct control loops are increased by the reference governor. As it can be observed in Fig. 21, when the reference changes, the flow rate decreases due to the new setpoint and to the is not only caused by the setpoint changes but also by disturbances in the inlet solar field temperature due to recirculation. The settling time in this change is $19 \mathrm{~min}$, the overshoot is $22 \%$ (see Fig. 23 ) and the steady state error is around $0.4{ }^{\circ} \mathrm{C}$. Then, at time $12.6 \mathrm{~h}$ the $\mathrm{TT} 8_{\mathrm{SP}}$ is changed to $65^{\circ} \mathrm{C}$. In this case, the time 405 spent in the change is $18 \mathrm{~min}$, the overshoot is $25 \%$ and the steady state error is around $0.3{ }^{\circ} \mathrm{C}$. At times 13.53 and $15.02 \mathrm{~h}$, two step changes are introduced with similar results as in the previous cases. At time $13.94 \mathrm{~h}$, both FT2 and FT3 are changed to $10 \mathrm{~L} / \mathrm{min}$. This fact produces that the temperature at the inlet of the MD module decreases. Therefore, the reference governor increases the setpoints of the direct controllers to reject this disturbance.

As can be observed in Fig. 21 the outlet solar field temperature is mainly controlled with the air cooler, since loop 1 is saturated due to high irradiance levels. The settling times obtained in the step changes are around 6 min and the steady state error is less than $0.2^{\circ} \mathrm{C}$ without overshoots.

415 As was tested in simulation, when valve 1 works in its linear range, an accurate control at the inlet of the heat exchanger is achieved (see Fig. 22). The settling times in this loop are around $15 \mathrm{~min}$ and the mean steady state error is less than $0.2{ }^{\circ} \mathrm{C}$. However, the overshoots are around $20 \%$. This fact is caused by $\mathrm{FF}$ actions, because it tries to reject disturbances produced by temperature coming from the distribution system (TT4). These disturbances occur because there is a time period where the outlet solar field temperature varies until it is established in its reference by loops 1 and 2. This situation produces the overshoots inside the module. Although these overshoots are undesirable, a 

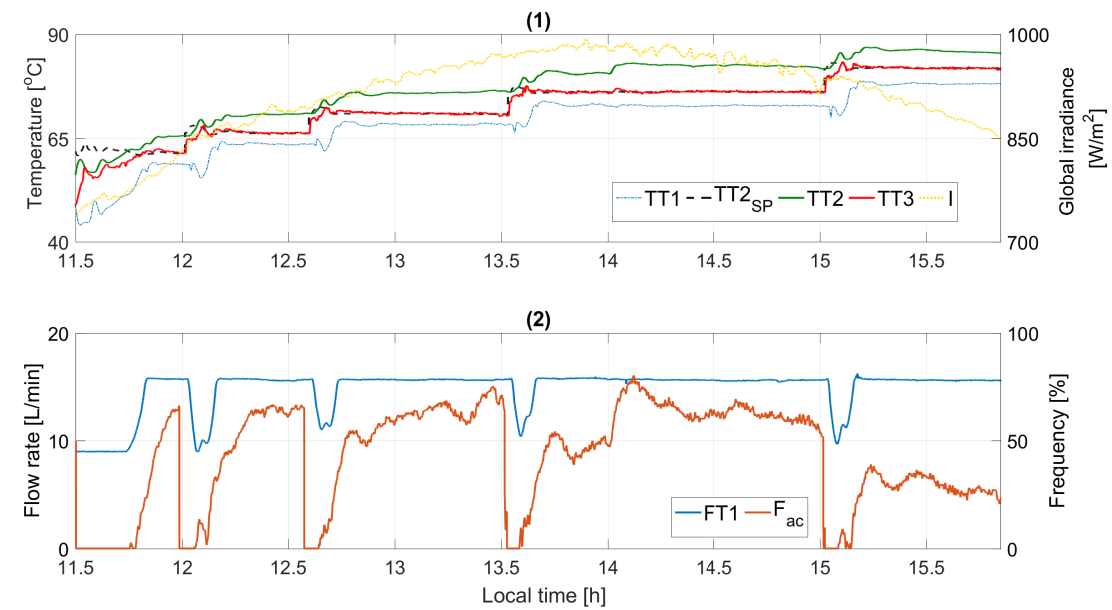

Figure 21: Experimental results of loops 1 and 2. (1) Reference (TT2 $\left.2_{\mathrm{SP}}\right)$, outlet solar field temperature (TT2), inlet solar field temperature (TT1), water air cooler temperature (TT3) and global irradiance (I) and (2) solar field flow rate (FT1) and air cooler frequency $\left(\mathrm{F}_{a c}\right)$.
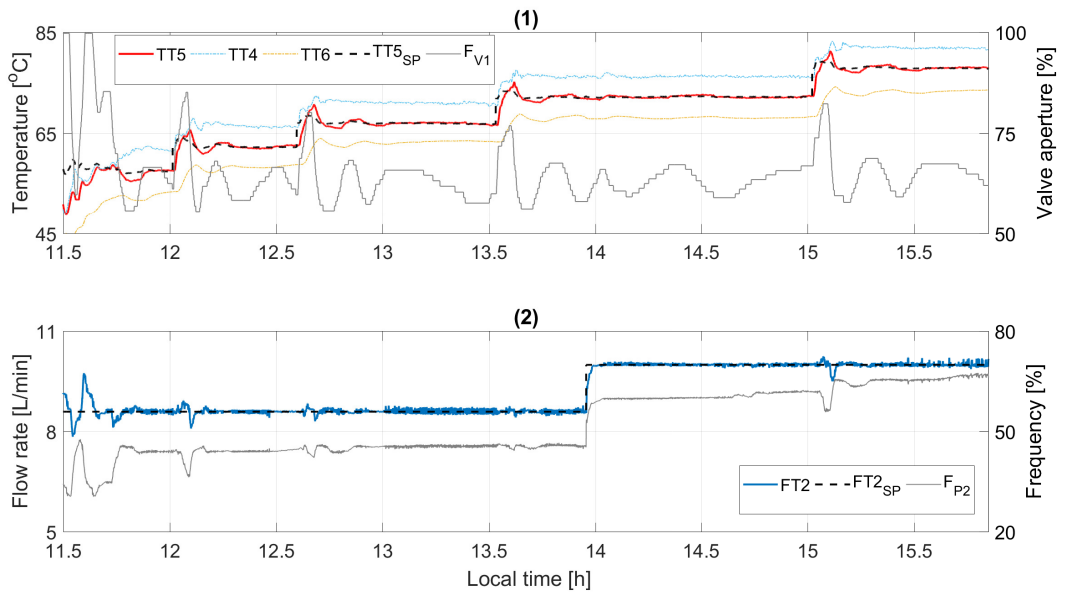

Figure 22: Experimental results of loops 3 and 4. (1) Inlet temperature to the hot side of the heat exchanger (TT5), water outlet temperature leaving the hot side of the heat exchanger (TT6), inlet distribution system temperature (TT4) and reference $\left(\mathrm{TT} 5_{\mathrm{SP}}\right)$ and valve 1 frequency $\left(\mathrm{F}_{\mathrm{V} 1}\right)$ and $(2)$ heat exchanger water flow rate $(\mathrm{FT} 2)$, reference $\left(\mathrm{FT} 2_{\mathrm{SP}}\right)$ and pump 2 frequency $\left(\mathrm{F}_{\mathrm{P} 2}\right)$.

tradeoff solution between settling time and overshoot allowed by plant operators in this operation mode has been reached, as has been pointed out before. 

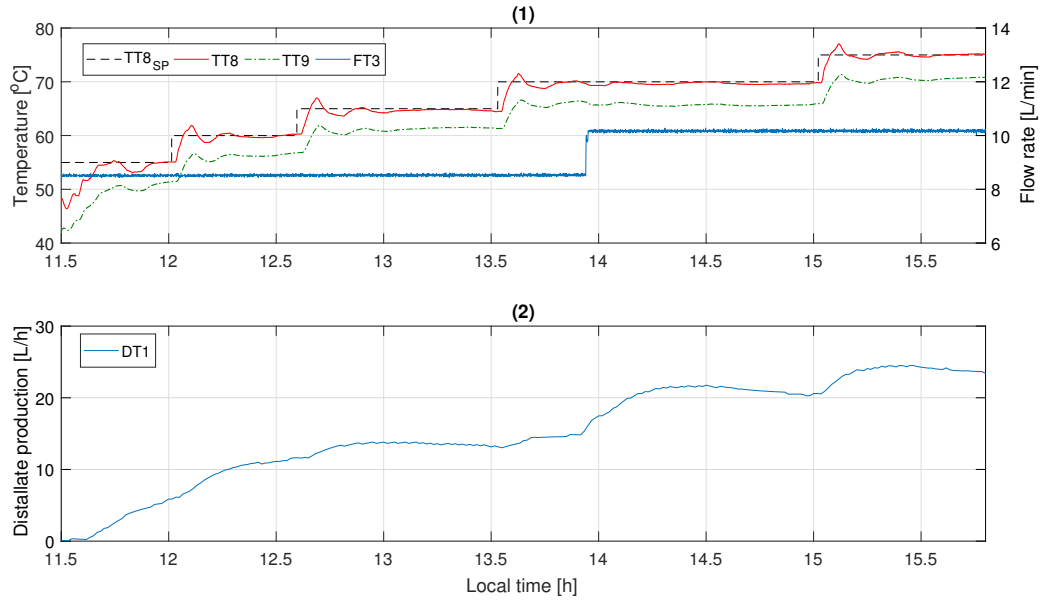

Figure 23: Experimental results at the inlet of the MD module. (1) Water outlet temperature leaving the cold side of the heat exchanger (TT8), reference $\left(\mathrm{TT} 8_{\mathrm{SP}}\right)$, inlet temperature to the cold side of the heat exchanger (TT9) and MD module water flow rate (FT3) and (2) distillate production (DT1)

\section{Conclusions}

This paper has addressed the development of a feedback control system in a solar membrane distillation facility. It has been accomplished using the most difficult operation mode, which is a challenge from a control point of view. Promising results have been obtained which allow us to draw the two following conclusions:

1. Settling times are considerably reduced. In a manual operation the time spent to establish an operating temperature inside the module is around 40-50 min, whereas with the control system is $20 \mathrm{~min}$.

2. A suitable operating temperature at the inlet of the distillation module, in the direct connection mode, can be obtained using the model-based reference governor and the control system in spite of disturbances. This task was highly difficult to follow in experimental campaigns with manual operation.

Future works will include the implementation of a control system able to manage all operating modes, following the approach in [24], as we can take advantage of all the work developed in this paper, and also testing multivariabledecoupling strategies. Moreover, the developed control layer should be integrated into a hierarchical control architecture aimed at maximizing the efficiency according to different metrics used in distillation processes or maximizing the daily production while reducing operational costs. 


\section{Appendix A. Nomenclature}

\begin{tabular}{|c|c|c|}
\hline Variable & Description & Units \\
\hline$A_{h e}$ & Heat exchanger area & $1.65 \mathrm{~m}^{2}$ \\
\hline$A_{s f}$ & Collector absorber cross-section area & $0.007 \mathrm{~m}^{2}$ \\
\hline$c_{f}$ & $\begin{array}{l}\text { Conversion factor to account for connections, } \\
\text { number of modules and } \mathrm{L} / \mathrm{min} \text { conversion }\end{array}$ & $\begin{array}{l}9 \cdot 2 \cdot 6 \cdot 10^{4} \\
(\mathrm{~s} \cdot \mathrm{L}) /\left(\min \cdot \mathrm{m}^{3}\right)\end{array}$ \\
\hline$c_{p}$ & Specific heat capacity & $\mathrm{J} /\left(\mathrm{kg} \cdot{ }^{\circ} \mathrm{C}\right)$ \\
\hline DT1 & Distillate production & $\mathrm{L} / \mathrm{h}$ \\
\hline $\mathrm{F}$ & Input frequency & $\%$ \\
\hline FT1 & Solar-field water flow rate & $\mathrm{L} / \mathrm{min}$ \\
\hline FT2 & Heat exchanger water flow rate & $\mathrm{L} / \mathrm{min}$ \\
\hline FT3 & MD water flow rate & $\mathrm{L} / \mathrm{min}$ \\
\hline$H$ & Global thermal losses coefficient & $5.88 \mathrm{~J} /(\mathrm{s} \cdot \mathrm{K})$ \\
\hline I & Global irradiance & $\mathrm{W} / \mathrm{m}^{2}$ \\
\hline$k$ & Static gain of FOPDT transfer functions & \\
\hline$L_{a}$ & Collector absorber tube length & $1.95 \mathrm{~m}$ \\
\hline$L_{e q}$ & Equivalent absorber tube length & $9.75 \mathrm{~m}$ \\
\hline LPF & Low pass filter & - \\
\hline$\dot{m}$ & Mass flow & $\mathrm{kg} / \mathrm{s}$ \\
\hline$n_{c s}$ & $\begin{array}{l}\text { Number of serie-connections in a collectors } \\
\text { group }\end{array}$ & 5 \\
\hline $\bar{T}$ & Equivalent absorber tube mean temperature & ${ }^{\circ} \mathrm{C}$ \\
\hline $\mathrm{T}_{a}$ & Ambient temperature & ${ }^{\circ} \mathrm{C}$ \\
\hline$t_{d}$ & $\begin{array}{l}\text { Representative time delay of FOPDT transfer } \\
\text { functions }\end{array}$ & $\mathrm{s}$ \\
\hline TT1 & Inlet temperature of the solar field & ${ }^{\circ} \mathrm{C}$ \\
\hline TT2 & Outlet temperature of the solar field & ${ }^{\circ} \mathrm{C}$ \\
\hline TT3 & Air cooler water temperature & ${ }^{\circ} \mathrm{C}$ \\
\hline TT4 & Inlet temperature of the distribution system & ${ }^{\circ} \mathrm{C}$ \\
\hline TT5 & $\begin{array}{l}\text { Inlet temperature to the hot side of the heat } \\
\text { exchanger }\end{array}$ & ${ }^{\circ} \mathrm{C}$ \\
\hline TT6 & $\begin{array}{l}\text { Water outlet temperature leaving the hot side } \\
\text { of the heat exchanger }\end{array}$ & ${ }^{\circ} \mathrm{C}$ \\
\hline TT7 & Outlet distribution system temperature & ${ }^{\circ} \mathrm{C}$ \\
\hline TT8 & $\begin{array}{l}\text { Water outlet temperature leaving the cold side } \\
\text { of the heat exchanger }\end{array}$ & ${ }^{\circ} \mathrm{C}$ \\
\hline TT9 & $\begin{array}{l}\text { Inlet temperature to the cold side of the heat } \\
\text { exchanger }\end{array}$ & ${ }^{\circ} \mathrm{C}$ \\
\hline$\alpha_{h e}$ & Heat exchanger heat transfer coefficient & $\mathrm{W} /\left(\mathrm{m}^{2} \cdot \mathrm{K}\right)$ \\
\hline$\beta$ & Irradiance model parameter & $0.11 \mathrm{~m}$ \\
\hline$\gamma$ & V1 aperture & - \\
\hline$\eta_{\text {he }}$ & Heat exchanger auxiliary factor 1 & - \\
\hline$\tau$ & $\begin{array}{l}\text { Representative time constant of FOPDT trans- } \\
\text { fer functions }\end{array}$ & $\mathrm{s}$ \\
\hline$\theta_{\text {he }}$ & Heat exchanger auxiliary factor 2 & - \\
\hline$\rho$ & Water density & $975 \mathrm{~kg} / \mathrm{m}^{3}$ \\
\hline
\end{tabular}




\begin{tabular}{llll}
\hline Subscript & Description & Subscript & Description \\
\hline ac & Air cooler & P2 & Pump 2 \\
C & Feedback control & SP & Setpoint \\
eq & Equivalent & V1 & Valve 1 \\
FF & Feedforward & 1 & Relative to FT2 \\
m & Model output & 2 & Relative to FT3 \\
P1 & Pump 1 & & \\
\hline
\end{tabular}

\section{Acknowledgments}

This work has been funded by the National R+D+i Plan Project DPI201456364-C2-1/2-R of the Spanish Ministry of Economy, Industry and Competitiveness and ERDF funds.

\section{References}

[1] M. R. Qtaishat, F. Banat, Desalination by solar powered membrane distillation systems, Desalination 308 (2013) 186-197.

[2] E. S. Mohamed, G. Papadakis, Advances of renewable energy powered desalination, in: Handbook of Clean Energy Systems, John Wiley Sons, Ltd, 2015, pp. 1-10.

[3] N. Ghaffour, S. Lattemann, T. Missimer, K. C. Ng, S. Sinha, G. Amy, Renewable energy-driven innovative energy-efficient desalination technologies, Applied Energy 136 (2014) 1155-1165.

[4] G. Zaragoza, A. Ruiz-Aguirre, E. Guillén-Burrieza, Efficiency in the use of solar thermal energy of small membrane desalination systems for decentralized water production, Applied Energy 130 (2014) 491-499.

[5] A. Cipollina, M. Di Sparti, A. Tamburini, G. Micale, Development of a membrane distillation module for solar energy seawater desalination, Chemical Engineering Research and Design 90 (2012) 2101-2121.

[6] M. Khayet, Solar desalination by membrane distillation: Dispersion in energy consumption analysis and water production costs (a review), Desalination 308 (2013) 89-101.

[7] E. Guillén-Burrieza, J. Blanco, G. Zaragoza, D.-C. Alarcón, P. Palenzuela, M. Ibarra, W. Gernjak, Experimental analysis of an air gap membrane distillation solar desalination pilot system, Journal of Membrane Science 379 (2011) 386-396. 
[8] E. Guillén-Burrieza, G. Zaragoza, S. Miralles-Cuevas, J. Blanco, Experimental evaluation of two pilot-scale membrane distillation modules used for solar desalination, Journal of Membrane Science 409 (2012) 264-275.

[9] J. D. Gil, A. Ruiz-Aguirre, L. Roca, G. Zaragoza, M. Berenguel, Solar membrane distillation: A control perspective, in: 23th Mediterranean Conference on Control and Automation (MED 2015), Torremolinos, Málaga, Spain, 2015, pp. 796-802.

[10] M. El-Bourawi, Z. Ding, R. Ma, M. Khayet, A framework for better understanding membrane distillation separation process, Journal of Membrane Science 285 (2006) 4-29.

[11] S. B. Abdallah, N. Frikha, S. Gabsi, Simulation of solar vacuum membrane distillation unit, Desalination 324 (2013) 87-92.

[12] V. Bui, L. T. Vu, M. Nguyen, Simulation and optimisation of direct contact membrane distillation for energy efficiency, Desalination 259 (2010) 29-37.

[13] J.-S. Lin, H. Chang, G. B. Wang, Modelling and control of the solar powered membrane distillation system, in: AIChE Annual Meeting, Minneapolis, MN, USA, 2011.

[14] H. Chang, G.-B. Wang, Y.-H. Chen, C.-C. Li, C.-L. Chang, Modeling and optimization of a solar driven membrane distillation desalination system, Renewable Energy 35 (2010) 2714-2722.

[15] H. Chang, S.-G. Lyu, C.-M. Tsai, Y.-H. Chen, T.-W. Cheng, Y.-H. Chou, Experimental and simulation study of a solar thermal driven membrane distillation desalination process, Desalination 286 (2012) 400-411.

[16] R. Porrazzo, A. Cipollina, M. Galluzzo, G. Micale, A neural networkbased optimizing control system for a seawater-desalination solar-powered membrane distillation unit, Computers \& Chemical Engineering 54 (2013) 79-96.

[17] E. F. Camacho, M. Berenguel, F. R. Rubio, D. Martínez, Control of Solar Energy Systems, Springer, 2012.

[18] L. Roca, M. Berenguel, L. J. Yebra, D. C. Alarcón-Padilla, Solar field control for desalination plants, Solar Energy 82 (2008) 772-786.

[19] C. O. Ayala, L. Roca, J. L. Guzmán, J. E. Normey-Rico, M. Berenguel, L. J. Yebra, Local model predictive controller in a solar desalination plant collector field, Renewable Energy 36 (2011) 3001-3012.

[20] L. Roca, J. L. Guzmán, J. E. Normey-Rico, M. Berenguel, L. J. Yebra, Robust constrained predictive feedback linearization controller in a solar desalination plant collector field, Control Engineering Practice 17 (2009) 1076-1088. 
[21] M. Beschi, M. Berenguel, A. Visioli, L. Yebra, On reduction of control effort in feedback linearization GPC strategy applied to a solar furnace, Optimal Control Applications \& Methods 37 (2016) 521-536.

[22] F. Eleiwi, I. N'Doye, T.-M. Laleg-Kirati, Feedback control for distributed heat transfer mechanisms in direct-contact membrane distillation system, in: 2015 IEEE Conference on Control Applications (CCA), Sydney, Australia, 2015, pp. 1624-1629.

[23] A. Alkhudhiri, N. Darwish, N. Hilal, Membrane distillation: a comprehensive review, Desalination 287 (2012) 2-18.

[24] M. Pasamontes, J. D. Álvarez, J. L. Guzmán, M. Berenguel, E. F. Camacho, Hybrid modeling of a solar-thermal heating facility, Solar Energy 97 (2013) $557-590$.

[25] A. Ruiz-Aguirre, D.-C. Alarcón-Padilla, G. Zaragoza, Productivity analysis of two spiral-wound membrane distillation prototypes coupled with solar energy, Desalination and Water Treatment 55 (2015) 2777-2785.

[26] J. Alvarez, L. Yebra, M. Berenguel, Adaptive repetitive control for resonance cancellation of a distributed solar collector field, International Journal of Adaptive Control and Signal Processing 23 (2009) 331-352.

[27] A. de la Calle, L. Roca, J. Bonilla, P. Palenzuela, Dynamic modeling and simulation of a double-effect absorption heat pump, International Journal of Refrigeration 72 (2016) 171-191.

[28] K. J. Åström, T. Hägglund, Advanced PID control. ISA-The Instrumentation, Systems, and Automation Society, Research Triangle Park, NC 27709 (2005).

[29] L. Ljung, Experiments with identification of continuous time models, IFAC Proceedings Volumes 42 (2009) 1175-1180.

[30] S. Skogestad, Simple analytic rules for model reduction and PID controller tuning, Journal of Process Control 13 (2003) 291-309.

[31] S. Skogestad, C. Grimholt, The SIMC method for smooth PID controller tuning, in: PID Control in the Third Millennium, Springer, 2012, pp. 147-175. 